\title{
DOGMA Y PROPAGANDA. LA CONSTRUCCIÓN IDENTITARIA FRANQUISTA A TRAVÉS DE LOS AUTOS SACRAMENTALES DE CALDERÓN. TEXTOS APOLOGÉTICOS EN LA PREHISTORIA DEL RÉGIMEN
}

\author{
JUAN MANUEL EscudERo BAZTÁN \\ Universidad de La Rioja
}

\begin{abstract}
Resumen
El presente trabajo estudia un texto inédito de Felipe Lluch con el título Del gran teatro de España, que resulta ser uno de los primeros textos del inicio de la posguerra que reivindica un teatro fascista, basado en la supremacía del teatro religioso del Siglo de Oro, en concreto de los autos sacramentales de Calderón de la Barca. El texto de Lluch es un magnífico ejemplo de las complejas relaciones entre literatura, dogma y propaganda.

Palabras clave: Felipe Lluch, posguerra, teatro del Siglo de Oro, autos sacramentales, Calderón de la Barca, propaganda.
\end{abstract}

\section{DOGMA AND PROPAGANDA. FRANCO'S IDENTITY CONSTRUCTION THROUGH THE SACRAMENTAL PLAYS OF CALDERÓN. APOLOGETIC TEXTS IN THE PREHISTORY OF THE REGIME}

\begin{abstract}
This paper studies an unpublished text by Felipe Lluch with the title Del gran teatro de España, which turns out to be one of the first texts of the beginning of the postwar period that claims a fascist theater, based on the supremacy of the religious theater of the Golden Age, specifically of the sacramental plays of Calderón de la Barca. Lluch's text is a magnificent example of the complex relationships between literature, dogma and propaganda.

Keywords: Felipe Lluch, postwar, Golden Age Theater, sacramental plays, Calderón de la Barca, propaganda.
\end{abstract}


La producción dramática clásica española tuvo una presencia bastante destacada en el teatro español de posguerra. Un buen puñado de títulos fueron llevados a las tablas en su condición de protagonistas destacados de una legitimación cultural diseñada por el Régimen de Franco. Si a esa postura revisionista, y continuista con los ideales imperiales de la España de los Austrias, se le añade el fuerte sesgo neocatólico de la España franquista en sus primeros años tras la Guerra Civil, se entiende que una parte significativa de ese teatro clásico fuera representada por el género sacramental, que parecía reunir tanto la idea de continuidad imperial como la idea de la restaurada España católica. Sin embargo, esa instrumentalización presentaba serios obstáculos al haber perdido el género sacramental su conexión con el público y contar con una estética hiperbarroca que había sufrido el desprestigio de las élites intelectuales a partir del siglo XVIII. En consecuencia, no parecía el auto sacramental a priori el género más adecuado para encarnar los valores de la nueva España que nacía tras la contienda. Sin embargo, se puede decir que, contra todo pronóstico, triunfó y se asentó como instrumento muy eficaz para abanderar la exaltación casi mística de una nueva sociedad de profundos valores cristianos. Salvo honrosas excepciones, como explico a continuación, sus cualidades artísticas y teatrales quedaron relegadas a un segundo plano. Los primeros textos apologéticos a este respecto se circunscriben a los inicios de la Guerra Civil, o inmediatamente tras su finalización. Son el principio de una larga estela de apropiaciones ideológicas de productos culturales por parte del régimen, que conforman un puñado de hitos significativos para la historia de la literatura ${ }^{1}$. Uno de estos hitos es, sin duda, la labor como director teatral y escenógrafo de Felipe Lluch. Su vocación teatral, como apunta García Ruiz, a quien sigo en estas líneas ${ }^{2}$, se inició en las veladas que tenían lugar en las Congregaciones Marianas de los jesuitas de Madrid y se consolidó después a través de las influencias escénicas de Cipriano Rivas Cherif y especialmente con el Teatro Escuela de Arte, el más importante de los

\footnotetext{
${ }^{1}$ Algunos de estos hitos vienen representados por textos de algunos intelectuales y escritores afectos al nuevo régimen, como Torrente Ballester (1937) o Giménez Caballero (1940-1944, 1943-1950, 1951).

2 Para la biografía y el itinerario profesional y personal de Lluch es de lectura obligada la monografía de García Ruiz (2010). Las líneas que siguen recogen numerosos datos ofrecidos por su autor con la única intención de contextualizar convenientemente el texto que analizo.
} 
grupos fundados por Rivas, que duró solo dos temporadas (1933-1934 y 1934-1935) y del que Lluch llegó a ser una pieza fundamental. Durante la Guerra Civil, Lluch permaneció en Madrid, vinculado a actividades teatrales en el entorno de la Alianza de Intelectuales Antifascistas para la Defensa de la Cultura. Durante los meses siguientes hasta el final de la guerra, Lluch experimentó un proceso de trans-formación políticocultural (motivado por cierto episodio que pudo tener consecuencias trágicas para él, como explico más abajo) convirtiéndose en un convencido falangista, que vio en el nuevo Estado fascista la oportunidad de realizar todos sus sueños de renovación teatral en un ambicioso Instituto Dramático Nacional. Sin embargo, lo único que logró fue el cargo de director del Teatro Español de Madrid a finales de 1940, que adquirió rango de Teatro Nacional y que pasó a depender del Sindicato del Espectáculo, en competencia con el otro Teatro Nacional recién inaugurado, el María Guerrero, dependiente del Ministerio de Educación. Lluch, pese a la menguada materialización de sus deseos, se lanzó con entusiasmo a revitalizar los clásicos españoles hasta su prematura muerte en junio de 1941, justo cuando había logrado situarse en condiciones de hacer mucho por la modernización de la escena española ${ }^{3}$. En este contexto vital que he esbozado muy por encima fue Lluch el autor de un texto inédito hasta fechas muy recientes ${ }^{4}$, titulado Del gran Teatro de España en el que intenta llevar a cabo el relato cabal de una historia sumaria del teatro español ${ }^{5}$. El texto fue compuesto en Madrid, hacia los últimos meses de la Guerra Civil española ${ }^{6}$. Y fue escrito como resultado de una honda crisis de conciencia que convirtió a un hombre conservador y católico, pero fiel a la República en el Madrid

\footnotetext{
${ }^{3}$ Ya en 1935 participó con varios artículos en el tricentenario de la muerte de Lope de Vega. Véase García Ruiz (2016) y Escudero Baztán (2017).

${ }^{4}$ El texto ha sido recientemente publicado de manera muy parcial por García Ruiz (2018), a quien agradezco me dejase leer el texto completo mecanografiado. Los comentarios que conforman estas páginas no habrían sido posible sin su extremada generosidad. Ya García Ruiz (2002) había dado noticia de la existencia de la obrita inédita de Lluch.

${ }^{5}$ Una «historia interna» (Diario 4 de enero de 1939). Véase García Ruiz (2018: 101).

${ }^{6}$ Se conserva en cuarenta y cinco cuartillas con numeración consecutiva en el margen inferior derecho, mecanografiadas en 1960 por su hijo, José Antonio Lluch. Solo se conserva una cuartilla autógrafa de Felipe Lluch. Remito a la bibliografía para la lista de artículos en los que Lluch —es obvio- se basa en Del Gran Teatro de España.

${ }^{7}$ En telegrama de 26 de agosto de 1936 a Rivas Cherif, cuñado de Manuel Azaña y
} 
posterior al 18 de julio del 36, en un acérrimo falangista. La anécdota de la conversión de Lluch es bastante conocida. Arranca en 1937, cuando es nombrado director del Teatro de Arte y Propaganda, integrado en la Alianza de Intelectuales Antifascistas, donde venía trabajando desde antes del comienzo de la guerra. El nombramiento no llegó nunca a ser efectivo porque Lluch fue inmediatamente denunciado, encarcelado y condenado por desafección al régimen a dos años de internamiento en un campo de trabajo. Pero gracias a la influencia de Rafael Alberti, María Teresa León y otros compañeros de la Alianza, a primeros de noviembre se le concedió la libertad condicional y regresó a Madrid a continuar con las actividades teatrales de la Alianza, que realizó a partir de entonces en un segundo plano, como ayudante de María Teresa León ${ }^{8}$. Lo más destacado que hizo el Teatro de Arte y Propaganda fue el estreno (26 de diciembre de 1937, teatro de la Zarzuela) de la Numancia cervantina, en versión de Rafael Alberti. El incidente, que pudo tener consecuencias dramáticas para Lluch, lo confinó a una especie de exilio interior, alimentado en exceso por largas horas de lectura de sus amados dramaturgos clásicos en el Ateneo o la Biblioteca Nacional y otros proyectos de diversa factura ${ }^{9}$. Silencio roto a mediados del 38 , cuando traba amistad con algunos componentes de la Falange clandestina en Madrid.

Felipe Lluch encarnó así el ideal de una nueva España, en la que se integraban sin distinción ninguna lo religioso, lo político y lo cultural, en una línea que combinaba el catolicismo cultural de Menéndez Pelayo, el sentido de la hispanidad de Ramiro de Maeztu y la retórica de José Antonio Primo de Rivera. Y fruto de esas ideas totalitarias junto a su extenso conocimiento del teatro áureo español fue la escritura de este Gran teatro de España. Una suerte de texto utópico que recoge en

hombre de inequívoca significación republicana, Lluch afirma: «Mantengo, como siempre, mi fe católica, apartado de todo partido político, ajeno a toda concepción fascista del Estado, contrario a toda violencia y fiel al poder legítimamente constituido» (García Ruiz, 2010: 67).

${ }^{8}$ En su novela Juego limpio (Buenos Aires, Coyanarte, 1959), María Teresa León dio un retrato muy personal de todo aquel mundo de la guerrilla teatral de la Alianza durante la Guerra Civil, e incluso del propio Felipe Lluch.

${ }^{9}$ El más importante, el Instituto Dramático Nacional, una auténtica toma por parte del Estado de toda la actividad teatral en España, de signo claramente fascista. Véase García Ruiz (2010: 274-280). 
parte los sueños frustrados de Lluch de desarrollar un verdadero teatro fascista $^{10}$. Ya a comienzos de 1939, anota este en su Diario (4 de enero de 1939) que podría escribir

un ensayo o resumen del desarrollo de los géneros dramáticos, de las teorías estéticas teatrales, de las características ideológicas y técnicas de cada época. Porque lo interesante y capital en la historia del teatro, según mi criterio, no son los autores y las obras, sino las ideas y sentimientos que informan las producciones y la técnica que se emplea para su redacción; es decir, la historia interna del teatro que será, casi, una historia de la cultura.

Con toda probabilidad, ese «ensayo» al que se refería era ese Del Gran Teatro de España, en el que Calderón es un referente central, empezando por las resonancias del título y siguiendo por la preeminencia que Lluch otorga al auto sacramental calderoniano en esa idea suya de un organicista Teatro Nacional, siguiendo la línea de pensamiento del hispanista alemán Ludwig Pfandl ${ }^{11}$, que le entusiasma y le lleva a considerar el teatro español como «un organismo vivo y continuo, $[\ldots]$ como obra de cultura, como constante nacional, como manifestación del espíritu español»(Diario, 4 de enero 1939, s. p.). Lluch distribuye su texto en trece secciones que denomina Normas, muy en la línea de la retórica falangista. Y lo estructura en tres partes: en la primera, los cinco puntos de su credo suponen una teoría restauracionista del Teatro Nacional; en la segunda $-\mathrm{y}$ más importante- (puntos 2 a 10) propone su concepción del teatro como una manifestación artística vitalista, y lleva a cabo un análisis de los géneros dramáticos en el Siglo de Oro, cuya cumbre es el auto sacramental, y de otros temas ancilares como los temas del Nacimiento, la Pasión de Cristo y la Inmaculada; la tercera termina con una utópica

${ }^{10}$ Nunca llegó a cristalizar ese ambicioso proyecto suyo de crear un Instituto Dramático Nacional. Como he señalado arriba, este quedó reducido a la subvención por parte del Estado de dos teatros: uno, el Español, puesto en manos de Falange; y otro, el María Guerrero, desde 1940 en manos de otra familia del franquismo, al cabo más poderosa, los nacional-católicos, más o menos monárquicos, que a los ojos de Franco representaban una opción menos revolucionaria y peligrosa.

${ }^{11}$ Su Historia de la Literatura nacional española en la Edad de Oro (1933) mereció severas críticas desde el ámbito liberal de los estudios literarios españoles; véase Castro (1934), Fernández Montesinos (1925), Meier (1934) y Anónimo (1942). 
y futurista mirada a la desiderativa restauración del «Gran Teatro de España».

Un poco más en detalle, la primera parte, que toma la estructura retórica de un credo, se hilvana a partir de una premisa principal, a la que se van aditando otros conceptos complementarios hasta modelar una idea bastante precisa de lo que significa el teatro para Lluch (pág. 8) ${ }^{12}$ :

Creemos - y así lo afirmamos de una vez y para siempre- en el teatro español. Creemos en un teatro nacional, religioso y popular; nacional sin patrioterismo, religioso sin ñoñez, popular sin chabacanería. Creemos en un teatro de España, para España y para el mundo.

Lluch habla de la necesidad de establecer un teatro de carácter nacional y popular, extensible a todos los españoles en su faceta de artefacto concebido para educar a la vez que para preservar la esencia hispánica (y la no menos importante proyección hacia el resto del mundo). Parte también de la convicción de que un teatro de este porte tiene que ser por fuerza un teatro religioso ( «en principio y en esencia todo teatro - como afirma Eugenio Montes ${ }^{13}$ - no es más que "liturgia"», pág. 9), pero en la línea bien visible del teatro religioso y catequético del Siglo de Oro, acompañado de una especie de religiosidad contenida, con la misión unívoca de edificar sobre la moral y el dogma una forma redimida y esencial de ser español (pág. 9).

Un teatro nacional y popular ha de ser, por fuerza, religioso. Pero un teatro religioso no es un teatro apologético, ni un teatro moralista, ni mucho menos gazmoño. Y nunca, claro está, un teatro simoníaco. Basta y sobra con que sea un teatro «edificante»; es decir, que edifique - y que construya - sobre la roca firme del dogma y de la moral, no sobre la arena de adventicias devociones ni en el aire de ventoleras místicas.

Y añade otra característica importante relativa a un teatro de clara orientación política, que no significa partidismo o pertenencia a un bando determinado, sino política en una acepción mucho más amplia

\footnotetext{
${ }^{12}$ Cito siempre el texto de Lluch por la página del original mecanografiado.

13 Eugenio Montes (1900-1982) fue escritor y uno de los primeros miembros de Falange Española.
} 
que se relaciona con la misión histórica de España, viejo imperio siempre emergente, como nación rectora de los destinos del mundo (pág. 11):

Un teatro religioso y popular - un verdadero teatro- será, además, político. No un teatro banderizo, es decir, de bando o parcialidad; no un teatro faccionario o de partido, sino un teatro que sea - por ser popular y religioso- expresión exacta del espíritu político, de la misión histórica de la nación de cuya vida es reflejo.

En suma (pág. 13):

Todo teatro nacional será, forzosamente, un teatro popular, religioso y político. Es decir, un teatro basado en el ser, en el creer y en el quehacer de todo un pueblo —en el ser "popular», en el creer «religioso», en el quehacer «político»- con escrupulosa fidelidad a la esencia misma de estas eternas raíces nacionales.

La parte descriptiva ocupa la mayor parte del escrito. Se analiza ese teatro - previamente definido como nacional, popular, religioso y político- a partir del comentario de una serie de rasgos considerados esenciales para entender su funcionamiento, aditando ideas fundamentales sobre la tragedia y la comedia del drama clásico español. En cierta medida, Lluch pretendía una reactualización de este teatro, visto como una salvaguarda de las esencias nacionales. Así, señala tres características esenciales relativas a los conceptos de «humanidad», «eficacia» y «espectáculo». Son, en todo caso, consideraciones generalistas, pero que ilustran perfectamente el ideario dramático que Lluch quiere inculcar en la sociedad española. En primer lugar, el concepto de «humanidad» es básico para comprender la dinámica de lo que considera apto para el teatro y, sobre todo, aquello que mejor funciona dentro de los mecanismos intrínsecos de la tragedia. Todo lo relativo al hombre es lo propiamente teatral, Y no hay mejor conflicto que las vicisitudes de la existencia humana, tan solo, como añadirá después, superado en belleza y hondura por la historia de la redención del hombre por la divinidad. Esta humanización tiene que ver con una crítica meridiana a los intentos de deshumanizar el arte llevado a cabo por un teatro de vanguardia que Lluch rechaza de raíz (pág. 15): 
Solo lo humano es teatral. Solo la pasión, la angustia, la vida humana son dramáticas. Los dioses no interesan si no se hacen hombres. Lo santos no apasionan si no son pecadores. Los héroes no conmueven si no son vulnerables. Ni la eterna y fría serenidad de los astros, ni el ciego y oscuro instinto de los brutos pueden ser objeto de conflicto dramático sino en cuanto influyen en el hombre. Por eso ha fracasado en el teatro la deshumanización del arte. Por eso fue estéril e ineficaz el llamado Teatro de Vanguardia.

La «eficacia» es otro de los ingredientes indispensable, entendida esta como una estética de lo intuitivo y lo real, todo aquello que se puede percibir de una sola vez, sujetado a un momento preciso, y no dilatado en el tiempo, ni necesitado de aclaraciones y apostillas. Su valor reside en la teatralización de un instante preciso, que no requiere de ningún corolario para su cabal comprensión (págs. 27-28):

Solo lo eficaz es teatral. Solo lo directo e intuitivo; solo lo que puede abarcarse con una sola mirada, solo lo inteligible por la sola y no repetida audición. [...] Lo teatral es un arte de realidades vivas, no una teoría de hipótesis. Solo cuenta lo hecho, lo que está presente ante el público. Todo lo que requiera prólogo, notas o premisas, todo lo que necesite explicación o comentario, previo conocimiento o ulterior exégesis, aunque lo haya escrito Shakespeare, no es teatro. El teatro, si es teatro, es siempre vivo, actual, presente. Lo teatral es únicamente lo directo y eficaz.

La tercera característica esencial guarda relación con el «espectáculo». Como señala Lluch, solo lo «espectacular es teatral». Y puntualiza que el teatro es necesidad de presencia corpórea, de espacio físico ocupado por la palabra. Fuera de este entorno materialista en sentido estricto se sitúan otras producciones artísticas menos físicas como la poesía o incluso la literatura dramática. La idea fundamental de Lluch aquí es que lo teatral es indisoluble a su representación y puesta en escena. Un teatro meramente de palabra no es teatro, lo que obliga en puridad, por ejemplo, a ubicar a Lope de Vega fuera de la órbita teatral, alejado del espectáculo, y más cercano a lo que se podría denominar la poesía dramática. En el lado contrario se sitúa Calderón, cuyo compromiso con el espectáculo es total, perceptible sobre manera en dos géneros que cultivó con éxito: las comedias mitológicas —léase las comedias de 
gran espectáculo escritas para la corte-, y el auto sacramental, que para Lluch está en la cúspide del teatro barroco (pág. 30):

Solo lo que admite y necesita una apariencia corpórea, una interpretación humana, una representación escénica es teatro. Lo demás será poesía, ensayo e incluso literatura dramática; pero teatro no. [...] Lope de Vega desconocía o despreciaba el espectáculo. Verdad es que Lope fue un poeta lírico $-\mathrm{O}$, si se quiere, épico- más bien que dramático. Calderón, en cambio, más teatral —más barroco- gustaba y usaba —e incluso abusaba- del espectáculo. De todo su teatro, lo más próximo a nuestra estética actual son las comedias mitológicas y los autos sacramentales, portentos de espectáculo.

El teatro es ante todo una forma vital fuertemente enraizada en lo popular, opuesto siempre a lo culto ${ }^{14}$, y unida, claro, al concepto de «eficacia» señalado antes. Es en este caso, espejo directo y vivísimo del teatro del Siglo de Oro, donde esta concepción teatral alcanzó su punto culminante frente a los opositores culteranos, quienes no tuvieron más remedio que esconderse "hasta morir en sus retretes eruditos, quienes durante años y años habían estado inútilmente alanceando con sus entecas, heladas, dulzonas plumas, prematuramente neoclásicas, el cálido, vigoroso y amargo teatro nacional» (pág. 32). Ahí es nada. Y termina por añadir (págs. 32-33):

¿Por qué esta dura y cruel batalla? Porque el teatro - y llegamos al término de esta larga pero necesaria y aleccionadora digresión histórica, para adentrarnos, por último, en el difícil terreno del

${ }^{14}$ Como señala el propio Lluch: «España —es decir, el mundo, porque el teatro del mundo, 'el gran teatro del mundo', es el teatro de España- siempre ha tenido, salvo en la plenitud gozosa de un siglo de unidad y perfección, dos teatros opuestos y rivales que se han odiado a muerte, aun antes de la vida - que es la escena-, como se odian en el vientre de su madre los hermanos a un tiempo concebidos. Estos dos teatros antagónicos, irreconciliables, son: el culto y el popular». Y añade después: «Eso — se nos argüirá- no es privativo ni peculiar del teatro; lo mismo ocurre en los demás géneros de la literatura y aun en las artes todas. Pero - reargüiremos tenaces-, lo que sí es privativo del teatro -y en esta premisa, casi axiomática, se basa nuestra estética teatral- es que lo popular vence a lo culto y acaba por conquistar su puesto, ascendiendo desde el corral al estrado; en tanto que en las demás artes o en los restantes géneros de la literatura es siempre, o casi siempre, lo erudito y cultural — salvo absurdas, momentáneas aberraciones de moda- lo que orienta, permanece y, a la postre, se impone y triunfa» (García Ruiz, 2018: 111-112). 
ensayo estético- es, en su lógica y natural representación escénica —es decir, como espectáculo ante un público cualquiera-, no una obra de cultura, sino una Forma Vital. Por consiguiente, instintiva y no intelectual. Y, por tanto, romántica y no clásica. Y lo vital, lo instintivo, lo romántico, es lo popular; en contraposición a lo erudito, lo intelectual y lo clásico, que es, en realidad, lo culto.

Todo esto supone, en última instancia, posar la mirada crítica sobre el auto sacramental, el primero entre los grandes géneros dramáticos, visto como punta visible de todo el andamiaje conceptual levantado por Lluch de ese Teatro Nacional de la nueva España, a la vez que simboliza la «superación cristiana del paganismo renacentista, el triunfo de lo ecuménico, la más bella forma del arte católico» (pág. 35).

Porque el auto sacramental [...] es, no solo la más perfecta expresión dramática de la raíz católica e imperial de España sino la más alta y bella manifestación de la tragedia —el teatro por excelencia que excede y supera incluso a la tragedia griega, cuanto la verdad, nobleza y armonía de la teología católica excede y supera a la falsa, rastrera y confusa mitología helénica.

Desde la perspectiva piramidal y jerárquica de Lluch, Calderón es el más sublime de los dramaturgos en cuanto que es capaz de llevar a cotas inimaginables el concepto dramático de la representación simbólica, la habilidad manifiesta de convertir en realidad escénica un puro concepto, y la posibilidad de dar vida en las tablas a la idea misma del término "teología». Todo esto es posible porque Calderón dramatiza en sus autos las más bella y perfecta de las tragedias, por encima, incluso, del concepto - señalado arriba- de «humanidad», porque la redención de Dios en el hombre lo hace partícipe de la transcendencia divina. A ojos de Lluch, entonces, no cabe hablar de tragedia más perfecta que aquella en la que se representa a «Dios hecho hombre, por amor al hombre, Dios muerto a manos del hombre, por amor al hombre, Dios dado en manjar al hombre, por amor al hombre» (págs. 37-38). La historia de la redención humana se erige, por tanto, como la culminación de un plan de designio divino que cobra forma y sentido en la genialidad del dramaturgo madrileño. Calderón no presenta esa historia salvífica de un modo directo, sensible y poético, sino de una manera indirecta, conceptual y teológica. Y entra en juego aquí el 
concepto de la alegoría, a partir de las ideas ya esbozadas en la década de los cuarenta por Valbuena Prat, en el que la utilidad de los espejos, que permite identificar el mundo de las letras humanas y divinas, se cristaliza a través del procedimiento bisagra de la técnica alegórica que siempre culmina, con alguna que otra excepción, en una orquestada exaltación eucarística (pág. 29):

En una síntesis vigorosa presenta la vida entera de la Humanidad según el dogma católico: Creación, Caída y Redención. Pero ésta no es ya dolorosa, sangrienta y terrible, como un recuerdo de la Pasión, sino alegre, incruenta, fácil, como obra de Dios. Todo está dramatizado, simbolizado, hecho acción y alegoría, con tal riqueza de medios y tal portento de profundidad e invención que sobrecoge y espanta por su grandeza casi infinita. Tal es, a grandes rasgos, el motivo fundamental de los autos de Calderón de la Barca, a quien se le pudiera llamar el poeta de la Redención, y con cuyo arte maravilloso muere el teatro religioso español».

Para Lluch la genialidad de Calderón va más allá incluso, pues es indiscutible que su talento creador incide una y otra vez sobre lo que él denomina el "reconocimiento ${ }^{15}$ ". Es decir, la habilidad artística del dramaturgo no radica en contar el argumento, y establecer los mecanismos de conexión entre el plano humano y el divino. Calderón no está interesado en que la tensión narrativa de su auto sacramental recaiga sobre el argumento y su alegorización. Lo que realmente alimenta su talento creador es recrearse en el cómo. «Lo que interesa, apasiona y conmueve en la tragedia griega y el auto sacramental es, no lo que ocurre, sino cómo ocurre; no lo que se hace, sino lo que se dice; no el

15 «Calderón, en la primera escena de sus autos, suele establecer el simbolismo dramático de su argumento. Este recurso, que así lo calificamos, no es tal sino en apariencia. En realidad, se trata, según creemos, de algo más hondo y trascendental. Este desvelar el argumento al iniciarse el espectáculo, este anular con ello el interés de la anécdota, es lo que, a nuestro juicio, presta al auto, no solo un nuevo argumento en pro de su clara filiación renacentista - recuérdense los introitos y argumentos-, sino su más alta y permanente categoría estética. Recuérdese, en efecto, que la más noble de las formas dramáticas hasta él conocidas - la tragedia griega - basa su interés no en la sorpresa sino en el reconocimiento. De estas dos fundamentales actitudes del hombre ante la obra artística —-sorpresa: actitud vital, romántica, perecedera; reconocimiento: actitud conceptual, clásica, perenne- la tragedia griega y el auto sacramental, con su argumento conocido de antemano, noble, arriesgada ascéticamente, desdeñando el triunfo fácil, prefieren la segunda» (García Ruiz, 2018: 117). 
hecho humano, sino la motivación dramática; no lo que es, sino el porqué de lo que es» (pág. 40). Calderón, además, añade con maestría otros temas fundamentales en sus autos relativos a su devoción mariana. No deja de autoproclamarlo el gran poeta de la Contrarreforma, y paladín de la Concepción Inmaculada de María ${ }^{16}$, que plasma con fervor casi reverencial a través de argumentos historiales de carácter tradicional y legendario, como puede observarse en autos de muy diversa factura como El cubo de la Almudena, restauración de la imagen de dicha advocación; El santo rey don Fernando, cuya base histórica es la conquista de Sevilla y la aparición de su patrona la Virgen de los Reyes, o A María el corazón, la bella y patética leyenda de la Virgen de Loreto. $\mathrm{O}$ a través del protagonismo de ciertas mujeres veterotestamentarias (Ruth, Abigail, Jael y otras), que funcionan en el plano simbólico como claras prefiguraciones de la Virgen María en autos tan conocidos como Las espigas de Ruth, La primer flor del Carmelo, ¿Quién hallará mujer fuerte?, Las órdenes militares, o La hidalga del valle.

Para Lluch siempre está vigente en su horizonte mental la idea de un teatro popular, de calado religioso, como principio necesario para restaurar y edificar los nuevos valores dramáticos que demandaba la naciente y verdadera España. Y nada mejor para esa labor de restauración que volver a rescatar del olvido una forma teatral pretérita que terminaría por convertirse, al fin, en la más rutilante modernidad. «La nueva comedia que se parecerá a la antigua como se parecen entre sí dos gotas de agua. La nueva comedia que será, como la antigua, vida, acción y poesía, bajo el alto cielo, sobre la seca tierra, frente a la mar undosa...» (pág. 40).

Como vaticinaba en la tercera, y última parte de su ensayo, dicho sea de paso, con muy escasa perspicacia augural, este sería el nuevo teatro que triunfaría de pleno en el año 2000 (tomando al pie de la letra el último epígrafe de su escrito, pág. 41):

Aquí está encerrada toda una grave y noble lección estética. El primitivo tablado de los cómicos de la legua, sencillo, abierto, ar-

16 «Calderón de la Barca, el poeta de la Contrarreforma, se proclamó en paladín de la Concepción Inmaculada de María y recogió todo el fervor popular, entrañable y legendario, de la España del siglo XVII para construir con solidez argumental y apologética la cúpula gallarda de una doctrina católica» (García Ruiz, 2018: 118). 
diente y enamorado, vencerá siempre al locutorio [sic] y laboratorio artificial, complicado, hermético, frío y cerebral. Frente a la industrialización, frente a la mecanización, sobre lo previsto y reglamentado, surge siempre - y siempre vencedora- la espontaneidad poética del genio creador. El teatro puede enfermar - casi agonizante está ya, el pobre- abrumado por la rutina, el maquinismo y los negocios. Pero llegará algún día —está alboreando ya- en que algún estudiante alocado volverá a cantar - como Agustín de Rojas- los nuevos versos de la Comedia Nueva. La nueva comedia que se parecerá a la antigua como se parecen entre sí dos gotas de agua. La nueva comedia que será, como la antigua, vida, acción y poesía, bajo el alto cielo, sobre la seca tierra, frente a la mar undosa...

Calderón era con sus autos sacramentales el mejor modelo que podía perfilarse para tan alta empresa. Comenzaba así una instrumentalización del dramaturgo para una nueva España, católica y reaccionaria a ultranza, que se perpetuaría a lo largo de toda la dictadura franquista con desigual fortuna en las tablas. En este sentido, se podría decir que la verdadera historia del género sacramental en la dictadura de Franco está todavía por escribirse.

\section{BIBLIOGRAFÍA CITADA}

ANÓNImo (1942): Necrológica de Ludwig Pfandl. Revista de Filología Española, 26, págs. 404-408.

CASTRO, A. (1934): Reseña de L. Pfandl, Historia de la Literatura nacional española en la Edad de Oro. Revista de Filología Española, 21, págs. 165-170.

ESCUDERO BAZTÁN, J. M. (2017): «Un hito previo al estudio del género sacramental en la posguerra española». Bulletin Hispanique, 119, núm. 1, págs. 133-142.

FERNÁNDEZ MONTESINOS, J. (1925): «Algunas observaciones sobre la figura del donaire en el teatro de Lope de Vega». En: Homenaje ofrecido a Menéndez Pidal. Miscelánea de estudios lingüísticos, literarios e históricos. Madrid, Hernando, vol. 1, págs. 469-504.

GARCía RuIZ, V. (2002): «Del Gran teatro de España: un Calderón falangista». En Arellano, I. (ed.): Calderón 2000. Kassel, Reichenberger, págs. 533-540. 
- (2010): Teatro y fascismo en España: el itinerario de Felipe Lluch. MadridFrankfurt, Iberoamericana-Vervuert.

- (2016): «Beneméritos cruzados de la cultura española»: el tricentenario de Lope en el ámbito conservador español». Anuario Lope de Vega, 22, págs. 110-151.

- (2018): «Del gran teatro de España: Calderón, la historia del teatro y la utopía nacionalista en 1940». Anuario Calderoniano, 11, págs. 101-119.

GimÉNEZ CABALleRo, E. (1940-1944): Lengua y Literatura de España y su Imperio (3 vol.). Madrid, Ernesto Giménez.

- (1943-1950): Lengua y Literatura de España (7 vol.). Madrid, Ernesto Giménez.

- (1951): Lengua y literatura de España (4 vol.). Madrid, Ernesto Giménez.

LLUCH GaRín, F. (1935): «La Pasión en el teatro clásico». Ya, 18 abril, pág. 8.

- (1935): «Tres comedias de Lope sobre san Isidro». Ya, 15 de mayo, s. p.

- (1935): «El auto sacramental, espectáculo perfecto». Ya, 20 junio, pág. 9.

- (1935): «El Teatro Nacional, museo y laboratorio». Ya, 28 junio, pág. 8.

- (1935): «El Teatro Nacional, escuela de buen teatro». Ya, 3 julio, pág. 9.

— (1935): «El Teatro Nacional, modelo de austeridad». Ya 8 julio, pág. 9.

- (1935): «Lope, olvidado por su patria». Ya, 10 agosto, s. p.

- (1935): «Sus obras renuevan la escenografía». Ya, 22 agosto, s. p.

- (1935): «El teatro religioso de Lope de Vega». Ya, 30 agosto, pág. 5.

- (1935): «La Inmaculada en los autos de Calderón». Ya, 7 diciembre, pág. 6; 13 diciembre, pág. 7.

- (1935): «El Nacimiento en el teatro español». Ya, 24 diciembre, pág. 7.

- (1936): «El drama de la Pasión en el teatro español». Ya, 9 abril, pág. 5.

- (1937-1939): Diario (inédito).

— (1940): «El teatro español». Tajo, 5, 29 junio, pág. 18.

— (1940): «El teatro popular». Tajo, 6, 6 julio, pág. 14.

- (1940): «El teatro religioso». Tajo, 7, 13 julio, pág. 14.

— (1940): «El teatro político». Tajo, 8, 20 julio, pág. 15.

— (1940): «El teatro nacional». Tajo, 9, 27 julio, pág. 14.

- (1940): «El teatro, forma vital». Vértice, 29, febrero, págs. 20-22.

- (1941): «Tres notas sobre lo teatral». Tajo, 36, 1 febrero, pág. 15.

- (1943): «El Auto sacramental». Revista Nacional de Educación, noviembre, págs. 7-17.

MeIer, H. (1934): Reseña de L. Pfandl, Historia de la Literatura nacional española en la Edad de Oro. Revista de Filología Española, 18, págs. 66-77. 
PfANDL, L. (1933): Historia de la Literatura nacional española en la Edad de Oro. Trad. J. Rubió Balaguer: Geschichte der spanischen Nationalliteratur in ihrer Blütezeit, 1929. Barcelona, Sucesores de Juan Gili.

TORRENTE BALleSter, G. (1937): «Razón y ser de la dramática futura». Jerarquía, 2, octubre, págs. 61-80.

\author{
Juan Manuel EsCUDERo BAZTÁN \\ Universidad de La Rioja \\ juan-manuel.escudero@unirioja.es \\ 0000-0003-0089-2785
}


